\title{
Influence of building shape and orientation on heating demand: simulations for student dormitories in temperate climate conditions
}

\author{
Martyna Mokrzecka ${ }^{1, *}$ \\ ${ }^{1}$ Wroclaw University of Science and Technology, Faculty of Architecture, Prusa 53-55, 50-317, \\ Wroclaw, Poland
}

\begin{abstract}
The aim of this paper is to investigate the impact of preliminary design decisions such as building shape and orientation on its heating demand. After analysing plans of forty student dormitories located in heating dominated climate (Dfb and $\mathrm{Cfb}$ ), eight typical plan layouts were identified and chosen for further analysis. Eight buildings were modelled using these plans and uploaded to dynamic simulation tool, Sefaira. Buildings have the same characteristics (surface, height, thermal properties, location etc.). The next step was to rotate the buildings at $45^{\circ}$ intervals and simulate the annual heating demand for each case. The results show that the shape influences the heating energy consumption. The difference between minimum and maximum heating demand in the chosen sample was $50 \%$. The square - shaped buildings have advantages in terms of heating energy consumption over $\mathrm{L}, \mathrm{U}$ and $\mathrm{C}$-shaped buildings as well as over rectangles with different shape factor. Orientation does not substantially influence the consumption in well insulated buildings. Last step of the research was to analyse the influence of functional layout on heating energy and internal comfort in a square-shaped building.
\end{abstract}

\section{Introduction}

Decisions about basic building design in the context of minimizing heat loss in the winter as well as heat gain in the summer are made at the very first stage of any architectural project. These decisions are critical in terms of final heating energy demand of the building. Adjusting building form, shape and orientation to local climate as well as planning size, orientation and shading for the glazing or choosing building materials can influence the final energy consumption up to $60 \%$ [1]. That is why successful design of energy efficient buildings requires special attention from the very first draft. Since only the orientation and shape can influence energy demand by $30-40 \%$ [2], the topic is being explored by researchers and practitioners. Aksoy and Inalli [3] simulated the energy demand in multi-storey building located in cold region of Turkey. They compare 3 models (shape factor: 1:1,1:2,2:1) with insulation $(5 \mathrm{~cm})$ by rotating them at $10^{\circ}$ intervals. They concluded that for a square building the best orientation is when the azimuth is $0^{\circ}$. For rectangular buildings the best case was

${ }^{*}$ Corresponding author: martyna.mokrzecka@pwr.edu.pl 
when the longer wall was facing south. The study was done for buildings with low insulation, located in dry summer continental climate (Elazig). For more insulated buildings and colder climate, Wang et al. [4]. analysed building orientation and aspect ratio (shape factor) of a single storey office building located in Montreal, Canada. The comparison between squareshaped plan, rectangular plan and L-shaped plan showed that the rectangular with plan proportions 2:5 is better for energy performance than square and L-shaped plan. TuhusDubrow and Krarti [5]. simulated the energy use for residential buildings located in five American cities. The optimisation includes variables: the building shape: rectangle, trapezoid, L, T, cross, $\mathrm{U}$ or H-shape, orientation and the geometric aspect ratio. The results indicate, that for buildings in heating-dominated climates the south-facing trapezoid performs the best in terms of annual heating energy. Square is only slightly worse. Kalina and Skorek [6] have simulated the energy use for office building. They compared architectural factors including: building rotation, shape \& height, interior design (layout of internal walls) and glazing percentage. Highest heating energy consumption appeared in high-raised building with lowest gross floor area. Neither rotation nor glazing percentage affects the heating energy consumption. Marcinkiewicz [7] performed simulations for single family house in temperate climate (Dfb). Architectural variables were: orientation, and size of glazing. The difference in energy consumption due to rotation and glazing (reference building had large windows towards south) was up to $17 \%$ (less favourable orientation was with longer façade oriented towards east and west). Change only in the size of the glazing resulted in max.15\% difference (in favour to less windows).

Despite the topic of energy optimization is gaining growing attention, there is still space for further research, especially in optimisation of well-insulated buildings located in temperate climate conditions. In this paper, the starting point is the recognition of most typical student residences plan. The analysis of 40 new (built after 2000) buildings has been made and most typical plans are selected. Those involve: square, rectangle with shape factor 1:2, 1:3,1:4, L, C and U-shape. Then the annual heating demand of buildings with selected plans is simulated, using Sefaira software. The changing variables are: shape and orientation. Other building characteristics (the level of insulation, windows to wall ratio, HVAC, etc.) remain constant. The simulations show that for temperate (Köppen climate classification $\mathrm{Dfb}$ ) climate condition, the most suitable building shape in terms of heating demand is square and the least suitable is $U$ shape. The difference in their heating demand is $53 \%$. The last step was to analyse the relation between functional layout of the building and its annual heating demand. 6 buildings from original sample were chosen, and 3 characteristic architectural layouts have been identified. Since the architectural layout affects building envelope, it was expected that buildings will differ in their heating demand. The results show $14 \%$ difference between the minimum and maximum annual heating demand.

\section{Method}

\subsection{Selection and comparison of typical student residences plans}

"The greening of the campus" movement started in 1970ies in USA has evaluated from simple on-campus actions to a complex stage, where cutting energy consumption and $\mathrm{CO} 2$ emission is an absolute must [8]. Campus sustainability has become an issue of global concern for university policy makers and planners [9]. Student residences are a part of this movement. For the analysis forty student dormitories has been chosen. The criteria were:

- Location in heating-dominated climate (Dfb and $\mathrm{Cfb}$ - Köppen classification)

- Energy efficient, well insulated (Classification of passive or low- energy building) 
Each student dormitory plan was drawn in a schematic, simplified way and oriented towards north direction. It was described with a prefix SD (student residence), a number, city and country location. The buildings were grouped according to their shapes. The most frequently appearing shapes were chosen for further analysis.

\subsection{Modelling and simulation settings}

Base on eight plans identified in analysis, eight virtual models were built in Sketchup. Models location was identical - suburbs of Hamburg, Germany. Buildings have different plan layouts, but the same surface $-4000 \mathrm{~m}^{2}$ and number of storeys ( 5 storeys, $3 \mathrm{~m} \mathrm{high}$ ). Then the buildings were uploaded to web-based, whole building simulations software, Sefaira. Sefaira works as a plugin for Sketchup or Revit (basic simulation is done within the plugin) and as web-based tool for more detailed analysis and optimization (using EnergyPlus engine). Thermal parameters of building envelope were as follows: walls, $\mathrm{U}=0.20 \mathrm{~W} / \mathrm{m}^{2} \mathrm{~K}$, roof, $\mathrm{U}=0.18 \mathrm{~W} / \mathrm{m}^{2} \mathrm{~K}$, ground floor, $\mathrm{U}=0.3 \mathrm{~W} / \mathrm{m}^{2} \mathrm{~K}$, glazing, $\mathrm{U}=0.9 \mathrm{~W} / \mathrm{m}^{2} \mathrm{~K}, \mathrm{SHGC}=0.4,30 \%$ of glazing at each facade. No external shadings, infiltration rate $=5 \mathrm{~m}^{3} / \mathrm{m}^{2} \mathrm{~h}$ (type: façade area). The heat gains were calculated based on following assumptions: 1 person per unit $\left(20 \mathrm{~m}^{2}\right)$, with sitting/light work activity, Heat gain $=4 \mathrm{~W} / \mathrm{m}^{2}$. Equipment power density $=10 \mathrm{~W} / \mathrm{m}^{2}$, Lighting $=10 \mathrm{~W} / \mathrm{m}^{2}$. The HVAC system was left as default (fan coil unit with central plant). In Sefaira Architecture, the options for choosing HVAC system are limited. In this research the focus is on analysing differences between shape and orientation, therefore the exact HVAC system was less important as long as it was the same in every building. Author did not intend to provide exact numbers related to heating demand, but to observe the correlation between shape, orientation and heating demand. To underline the importance of correlation over exact numbers on heating demand, the abstract value " $x$ " was used to describe the heating demand. $\mathrm{X}$ was used to define the lowest annual heating demand per square meter in the sample. The variations were described in relation to this value, for example $1.2 \mathrm{x}, 0.8 \mathrm{x}$. Each building was rotated at $45^{\circ}$ interval, which gives 36 simulated building variations. For the further simulations of square-shaped buildings the same settings were used.

\section{Case buildings}

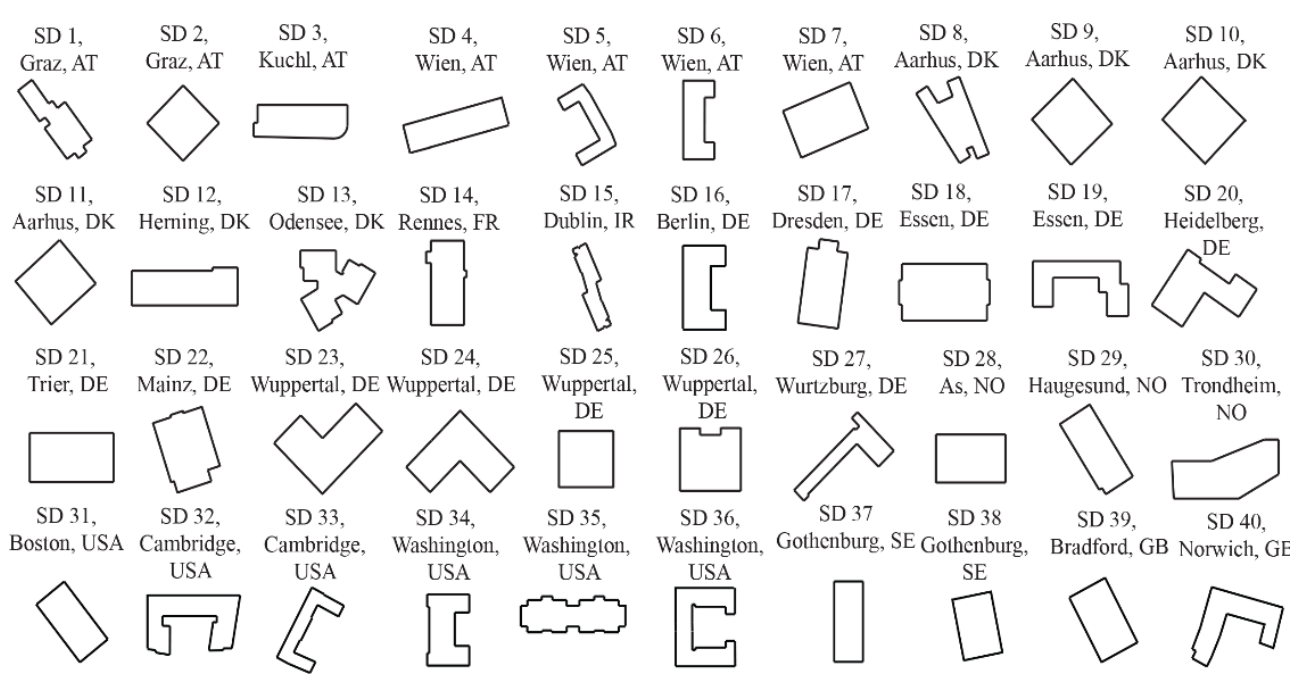

Fig. 1. Simplified plans of 40 energy-efficient student residences. Plans are oriented towards north direction. 
Fig. 1 shows the simplified plans of forty energy-efficient student residences. Majority of them are rectangular, with different shape ratio (proportion between two sides of rectangle) - about $45 \%$. $12.5 \%$ of the plans are U-shapes, $15 \%$ L-shapes, $15 \%$ squares, $7.5 \mathrm{C}$-shapes, $5 \%$ irregular shapes. From rectangular shapes, square, L-shape (symmetrical and elongated), U-shape (two different proportions) and rectangle (with shape ratio 2:1, 3:1 and 4:1) are chosen for energy simulation.

\section{Simulation results}

Fig. 2. shows student residences models built in Sketchup and prepared for Sefaira analysis. Each building has the same: surface $\left(4000 \mathrm{~m}^{2}\right)$, number of storeys (5), window to wall ratio (30\%), envelope and HVAC properties. They differ only in the plan shape or shape factor.
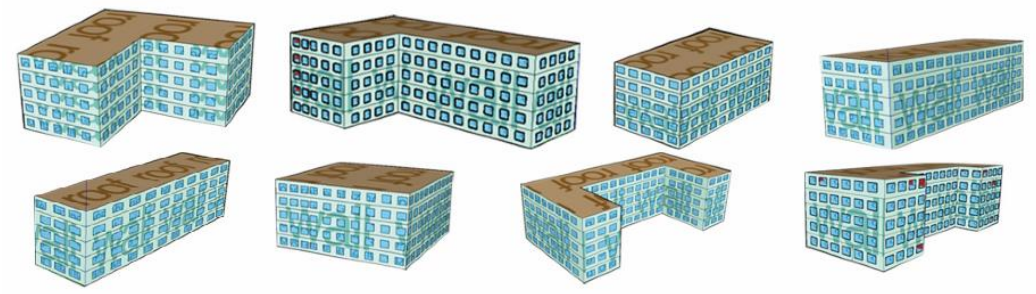

Fig. 2. 8 types of student residences, screens from Sefaira

Firstly, the annual heating demand for each building was simulated (Sefaira uses the $\mathrm{kWh} / \mathrm{m}^{2} /$ a units). Then each building was rotated at $45^{\circ}$ intervals and for each case the annual heating demand was calculated. This gives 45 outcomes marked with a letter and number (fig.3).

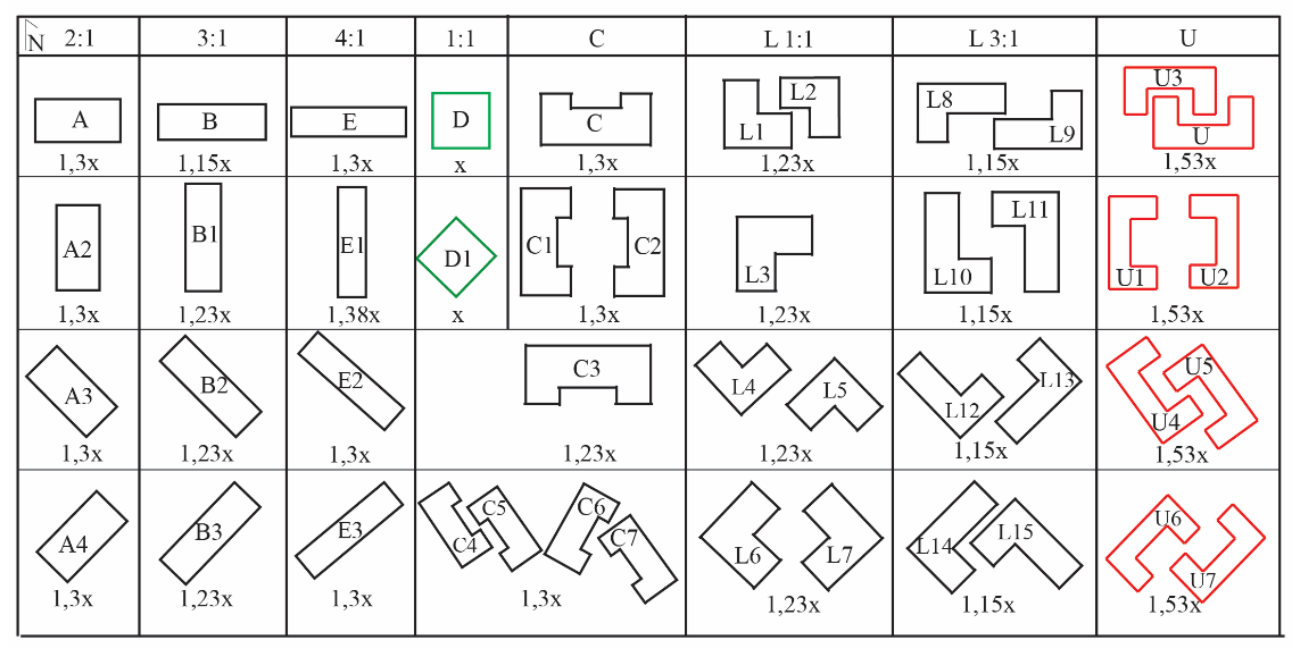

Fig. 3. 8 types of student residences and their heating demand. Green colour indicates the lowest heating energy demand, whereas red the highest.

There is a $53 \%$ difference between the simulated minimum and maximum annual heating energy demand. When the annual heating energy demand values of the buildings with different shapes are compared with each other it is determined that square-shaped plan (D; D1) is the most advantageous in terms of heating energy. The least advantageous plan is U-shape plan, with 53\% higher heating energy demand than square shape. $15 \%$ worse than 
building D performs building B (3:1 rectangle elongated towards East-West axis) and buildings L8 to L15 (elongated L-shape in all simulated positions). 23\% worse than building D perform: building B1-B3, L1 to L7 (symmetrical L), C3. 30\% worse perform buildings: A-A4 (2:1 rectangle), E, E2, E3 (4:1 rectangle in all positions but elongated towards NorthSouth axis, C in all positions but C3. 38\% worse performs E1 building and 53\% worse perform U-shaped building in all cases.

With building plan shapes being identical, the change in orientation position does not affect heating energy demand substantially. In some cases, it stays stable, despite changing the orientation. The example is square shape (building D and D1), 2:1 rectangle (A-A4), L-shapes (L1-L15) and U-shapes (U-U7). There is an $8 \%$ difference between B and B1 buildings (favourable position is longer side perpendicular to North-West axis over longer side parallel to North-West axis). There is $8 \%$ difference between $\mathrm{E}$ and E1 buildings with the same correlation as in previous case. There is also a 7\% difference between $\mathrm{C}$ and $\mathrm{C} 3$ buildings in favour to $\mathrm{C} 3$ position (more facades oriented towards the south).

\section{Shape and layout optimisation in student residences}

Simulations show that the most favourable plan layout in terms of reducing energy consumption is the square shape. In the analysed sample of forty dormitories, six buildings are square-shaped. In the simulation, one of the assumption was that all facades have the same window to wall ratio. It was done to simplify the case, but also because of the building function. Student residences can be classified as residential buildings but in terms of layouts they have similar plans to hotels. Many rooms, or small living units are organised along corridors. The function encourages to use elongated shapes like rectangles, with central corridors and rooms on both sides. Usually the plans are symmetrical, which means that also facades are symmetrical. In this term, student residences are less flexible in response to layout and facade changes than residential homes, variations are possible though. It is similar in square-shaped dormitories. Below, the plans of six square shape student dormitories from the original sample are presented.
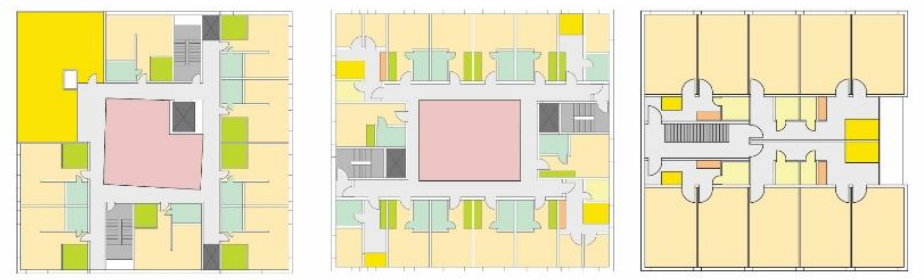

$\square$ student room $\square$ private kitchen $\square$ shared kitchen $\square$ private bathroom $\square$ shared bathroom $\square$ dining space $\square$ staircase
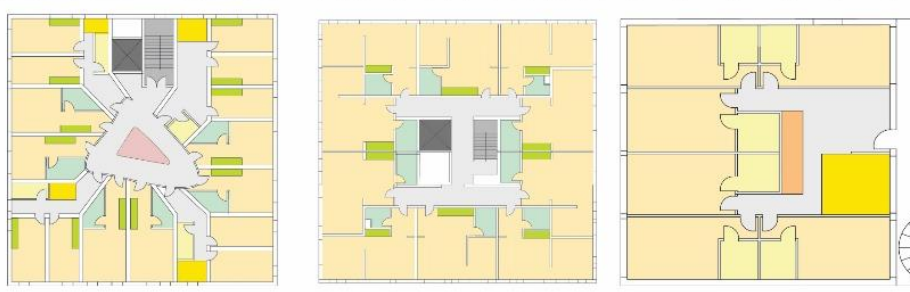

$\square$ corridor घelevator $\square$ atrium

Fig. 4. Six layouts of square-shaped student dormitories. Colours represent room functions.

One building is designed with rooms along the whole building perimeter and the corridor as a core, without any windows. Three have corridors organised around covered atrium. Rooms and additional staircases are around the perimeter of the building. Their facades are identical or very similar in terms of window to wall ratio and window layout. One building plan has the corridor in the centre together with kitchens and bathrooms. Rooms are located on two 
sides of the corridor. That generates differences in the facades and allows to differentiate the facades. The staircase in the last plan is located outside the building, which allows to reduce windows on one façade.

Three models have been built in Sketchup and analysed in Sefaira. They are all square shaped, with all the properties the same as in previous simulation. The first one has all facades identical - it is building D from previous simulation (Fig.3). The second one has all facades identical and a roof glazing (D2). Third one has two facades identical and two with smaller glazing percentage $(10 \%)$ (D3). The location is the same as in the previous models.
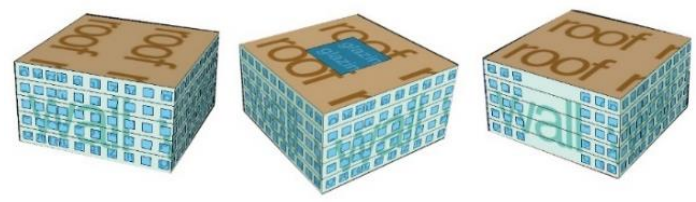

Fig. 5. 3 types of square-shaped student residences. From the left: building D, D2, building D3.

Simulations show that the decision on the architectural layout of the building with the same shape influences the heating energy consumption. D3 was the building with the lowest heating energy consumption. The highest energy consumption has D2 building. Staying with the reference consumption from previous simulations, we have the relation: $D=x$, so $\mathrm{D} 2=1.07 \mathrm{x}, \mathrm{D} 3=0.93 \mathrm{x}$. The orientation has no influence on their consumption.

\subsection{Internal comfort and risk of overheating}

Indoor thermal conditions in buildings D, D2 and D3 were analysed. PMV (predicted mean vote) model was taken under consideration along with ASHRAE 55 standard. Calculations were made using Sefaira. Buidings D and D2 have the same internal layout with rooms around the perimeter and internal core. 21 thermal zones were modelled on each floor. In building D3 19 thermal zones at each floor appeared (fig.6).
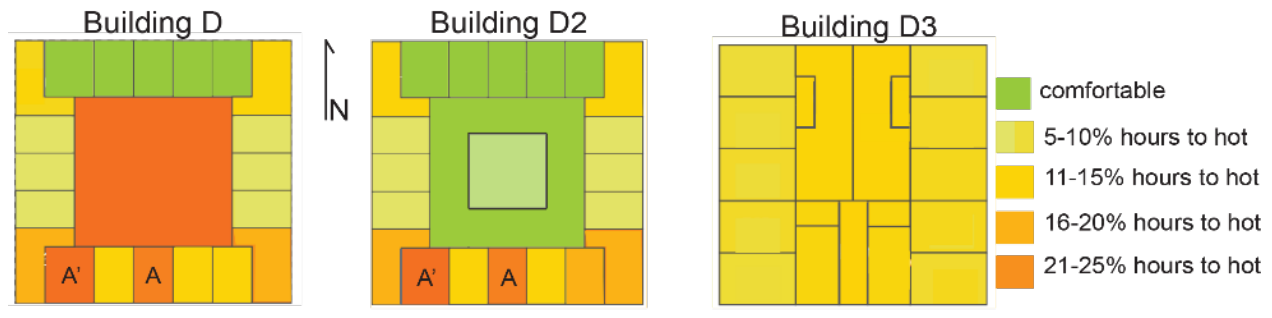

Fig. 6. Selected ( $4^{\text {th }}$ floor) layouts of buildings D, D2, D3. Colours indicate percentage of time during the year, when zones are overheated.

Winter clothing indoors were set to $1 \mathrm{Clo}$, summer to $0.5 \mathrm{Clo}$. Activity level=1.1 Met. Air velocity is assumed to be constant at $0.1 \mathrm{~m} / \mathrm{s}$. Dry bulb temp; mean radiant temp. and relative humidity were calculated in EnergyPlus accordingly characteristics described in chapter 2.2. Sefaira software shows the result of comfort value as "pass" or "fail" for each defined zone. Additionally, the information about percentage of "too hot" or "to cold" occupied hours is shown. Zone "passes" if the PMV is between -0.5 and 0.5 for $98 \%$ percent of time (PMV scale is between -3 (cold) and +3 (hot). Comfort temperature was defined between $20.3^{\circ} \mathrm{C}-$ $24.3^{\circ} \mathrm{C}$ in winter and up to $26.3^{\circ} \mathrm{C}$ in the summer (ASHRAE 55).

Fig. 7 shows the percentages of all comfortable and uncomfortable zones in building D, D2 and D3. In all uncomfortable zones the problem was the overheating during spring and summer months (PMV=1, PMV=2). Building D2 reached the highest percentage of 
comfortable ("passing") zones - 49\%. Comfortable zones were all rooms on north façade (excluding corner rooms) at all floors, core zone (excluding top floor), rooms on east and west façade at first three floors. Most turbulent zones were rooms located in the middle of south façade and on south-west and south-east corners (fig.6: A and A'). In building D 39\% of zones has PMV between -0.5 and 0,5 for $98 \%$ of time. Similarly, to D2, comfortable were rooms on the northern façade and east and west at first two levels. Core and two middle rooms at southern façade were the hottest zones (operative temperature reaches $27-28^{\circ} \mathrm{C}$ in summer months).

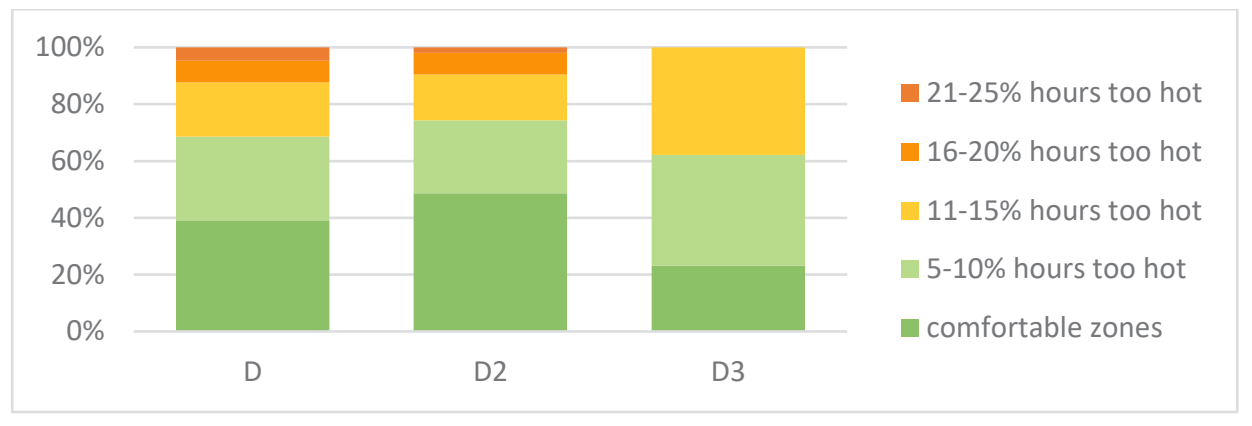

Fig. 7. Zones in building D, D2 and D3. Chart shows the percentage of comfortable zones and zones where $\mathrm{PMV}>0.5$ for indicated time.

In building D3 the percentage of comfortable zones was the lowest (23\%), but at the same time the max. time of overheating was $15 \%$. Majority of rooms were overheated for $5-10 \%$ of time. Zones in the core of the building were mostly overheated for $11-15 \%$ of time.

\section{Discussion and results}

The results of the simulations performed on buildings with different shapes show some similarities to results obtained by Aksoy and Inalli [3] and Tuhus-Dubrow and Krarti [5] studies, however the sense of making direct comparisons between simulations done for buildings with different location and envelope properties is questionable. Why is it questionable? The design variables which influence building energy consumption are complex, intercorrelated and strictly dependent on every decision made during the design process. Whereas the general statements (such as: compactness is positively corelated with building heating consumption) are valid for similar climate conditions, the importance of them in final energy consumption breakdown will differ accordingly to dozens of factors that corelate with them during the design process. That is why using the dynamic simulation tools gives designers the power to explore the tailored opportunities of energy optimisation in an early design stage [10]. When it comes to new project design, every building should be treated as individual case. At the same time, the process of optimisation could be fostered by providing guidelines on how to create assumptions for certain building types located in certain climate. For student residences the assumption from presented research is, that the most favourable plan in terms of heating demand is square. In terms of indoor environmental quality however, square might be problematic. It implies the creation of functional layout with central, internal core. As comfort analysis shows, internal, windowless core reaches high temperature during summer months. It also needed constant artificial lighting, what affects the electricity consumption. Second functional variation of square-shaped student residence is the design of centrally located atrium covered with operable glass. It performs better in comfort analysis than windowless core. Only last storey is overheated due to direct solar 
gains. Solar gains could be eliminated with external shading over the skylight. It would lead to artificial lighting, but only when the overheating problem occurred.

When analysing the layouts of square - shaped student residences (fig.4), assumption could be made, that central core is most common solution for this building type. It has an economical explanation. Central core allows to create more rooms at one floor. Rooms are usually small (16-20 $\mathrm{m}^{2}$ including the bathroom and kitchenette) with windows oriented towards one direction. Analysis showed in figure 6 suggest that the size of rooms does not substantially influence the overheating time, but the relation between the size of the windows and room size does. Rooms marked as A and A' in buildings D and D2 have two windows. All other rooms at southern façade have one window. The overheating time for rooms with two windows is much longer than for the others. This could be neutralised with using external shading. Surpassingly, none of buildings which plans were used for the analysis has external shading.

The least favourable shape in terms of heating demand is U-shape. It is not a very common shape for student residence function (12.5\% in the sample). U shape generate problems not only with heating demand but also limits the access to natural light. It however allows to maximize the number of rooms in the building and is often used when the site is small.

While the orientation affects the energy demand even for highly insulated buildings, the influence of rotation is much less significant. From eight analysed shapes, five did not differ after rotation. In remaining three, the difference in heating demand was $8 \%$. The building is more likely to be affected when the difference between their sides proportion is 1:3 or bigger. Since elongated rectangle is the most common shape for student residences $(45 \%$ in analysed sample), rotation should be considered in majority of student residence designs.

\section{References}

1. N. Lechner, Heating, cooling, lighting: sustainable design methods for architects (John Wiley \& Sons, 2009)

2. V. Brophy, J.O. Lewis, A green vitruvius: principles and practice of sustainable architectural design (Earthscan, 2011)

3. U.T. Aksoy, M. Inalli, Build. Environ. 41, 1742-1754 (2006)

4. W. Wang, H. Rivard, R. Zmeureanu, Adv. Eng. Inform. 19, 5-23 (2005)

5. D. Tuhus-Dubrow, M. Krarti, Build. Environ. 45, 1574-1581 (2010)

6. J. Kalina, J. Skorek, Instal, 1, 3-7 (2012)

7. P. Marcinkiewicz, Środowisko mieszkaniowe, 16, 23-33 (2016)

8. C. Erickson, C. Skoglund, Sustainability: The Journal of Record, 1, 57-72 (2008)

9. M.M. Sesana, et al., Journal of Building Engineering, 6, 54-64 (2016)

10. K. Konis, A. Gamas, K. Kensek, Solar Energy, 125, 161-179 (2016) 